\title{
Impact of type 1 diabetes and its duration on wall- to-lumen ratio and blood flow in retinal arterioles
}

Adrian Stefanski ( $\square$ astefanski@gumed.edu.pl )

Hypertension and Diabetology Department

Jacek Wolf

Joanna Harazny

Eliza Miszkowska-Nagórna

Bogumił Wolnik

Krzysztof Narkiewicz

Roland Schmieder

\section{Article}

Keywords: type 1 diabetes, retinal microcirculation, Scanning Laser Doppler Flowmetry, SLDF, wall-tolumen ratio, arterioles remodeling, subclinical organ damage, cardiovascular disease

Posted Date: August 1st, 2022

DOI: https://doi.org/10.21203/rs.3.rs-876521/v2

License: (c) (i) This work is licensed under a Creative Commons Attribution 4.0 International License.

Read Full License 


\section{Abstract \\ Background}

Subclinical damage to both the small and large vessels may contribute to the development and progression of cardiovascular disease. Scanning laser Doppler flowmetry (SLDF), an established method used to measure retinal microcirculation, has been successfully applied in hypertensive and post-stroke patients.

\section{Methods}

Retinal microcirculation was assessed in 158 patients with type 1 diabetes and 38 age-matched healthy controls. The diabetics were divided into 3 groups: group A with diabetes duration $<12$ months, group B with diabetes with 1-10 years, and group $C>10$ years of diabetes. Retinal capillary structure and perfusion were evaluated using a Heidelberg retina flowmeter and automatically analyzed with full-field perfusion imaging.

\section{Results}

Age and BMI were comparable in all the diabetic patients and the controls (mean age $24.8 \pm 4.7$ years, mean BMI $22.9 \pm 4.1)$. In the univariate analyses, RCF was significantly higher in group A $(297 \pm 121$ arbitrary units $[A U])$ vs group $B(236 \pm 52 \mathrm{AU} ; \mathrm{p}=0.007)$ and group $\mathrm{C}(236 \pm 70 \mathrm{AU} ; \mathrm{p}=0.008)$ and comparable to that of the controls $(p=0.46)$. Additionally, the WLR was highest in group $C$ compared to the other diabetic subgroups and controls $(p=0.47)$.

\section{Conclusions}

New-onset diabetes is associated with an increase in RCF, which then gradually decreased with the duration of the disease. Structural changes of the retinal arterioles estimated via WLR are evident later in the course of diabetes, especially when the disease duration exceeded 10 years.

\section{Introduction}

Diabetes mellitus (DM) is one of the most important independent risk factors for the development and progression of cardiovascular disease including ischemic heart disease, stroke, chronic kidney disease, limb amputations, and blindness $(1,2)$. A better understanding of the mechanisms underlying cardiovascular disease may therefore lead to the development of more effective preventive measures. Increased DM-related cardiovascular risk may be partly mediated by functional and structural alterations of blood vessels resulting from nitric oxide synthase (NOS) reduction(3). Importantly, DM and hypertension frequently coexist and share several pathophysiological mechanisms, which further 
multiplies the cardiovascular risk(4). Although this relationship is evident in type $2 \mathrm{DM}$, much less is known about the development and progression of hypertension in type 1 diabetes (T1DM). In these patients, blood pressure (BP) elevation occurs much later than in type 2 patients and may be a consequence rather than a cause of kidney disease. The majority of studies on T1DM have focused on large artery function and structure; however, the available evidence linking T1DM to microcirculation abnormalities is derived primarily from studies assessing renal vascular function(5). Previous studies of the eye fundus have focused on the ophthalmological context only(6), yet retinal microcirculation may be a very important source of information about the condition of the cerebrovascular system and its pathologies(7). Scanning laser Doppler flowmetry (SLDF) is a non-invasive technique used to evaluate retinal microcirculation. This method has been also successfully employed in testing healthy volunteers as well as patients with hypertension or chronic kidney disease(8-10). To the best of our knowledge, SLDF has not been used to evaluate retinal microcirculation among young adults with T1DM. The aim of our study was therefore to investigate the remodeling of the small retinal arteries and blood flow alterations in T1DM patients.

\section{Materials And Methods}

\section{Patients:}

A total of 174 consecutive T1DM patients were enrolled in the study from the Hypertension and Diabetology Clinic and the tertiary care Diabetes Outpatient Clinic at the University Clinical Center in Gdańsk.

The only inclusion criterion for the study was a diagnosis of T1DM based on the European Society of Cardiology 2019 Guidelines(11), which included the presence of the specific antibodies for T1DM and/or a reduced serum C-peptide level. Additionally, the control group $(n=38)$ consisted of age-matched healthy volunteers who had not been diagnosed with diabetes or hypertension.

\section{Retina microperfusion and morphology of retinal arteriole measurements:}

Retinal capillary flow (RCF) and the retinal arteriolar outer vessel (VD) and inner lumen (LD) diameters were evaluated using confocal scanning laser Doppler flowmetry (SLDF) technology by Heidelberg retina flowmetry (Heidelberg Engineering, Hidelberg, Germany) at a scanning laser wavelength of $670 \mathrm{~nm}(12)$. Only images with sufficient quality were analyzed. Arteriolar vessels with a diameter between 70 and 140 $\mu \mathrm{m}$ were measured in the temporal superior quadrant of the right retina. In one case, due to a lack of transparency in the right eye, the left eye was selected.

A 3D retinal volume of $2.56 \times 0.64 \times 0.30 \mathrm{~mm}$ was scanned in 2 seconds, and an image of $2.56 \times 0.64$ $\mathrm{mm}$ in 2D was averaged. The pixel resolution of the image was $10 \times 10 \mu \mathrm{m}$; however, for the morphological vessel analysis, the pixel resolution was increased to $1 \times 1 \mu \mathrm{m}$ by Akino interpolation. The 
retina images were analyzed using AFFPIA version 4.10 software(13). The wall-to-lumen ratio (WLR) of the retinal arterioles was calculated using the formula:

WLR $=($ VD - LD) $/$ LD. Wall thickness $(W T)$ was calculated by the formula: WT $=($ VD-LD)/2 and wall cross section area (WCSA) by the formula: $W C S A=\left(V D^{2}-L D^{2}\right) * 3,14 / 4$.

\section{Study design:}

The fundi of the right non-mydriatic eyes of the patients were measured in the sitting position in the morning between 8:00 and 12:00 after 10 minutes of rest(14). For each patient, a pre-test measurement was performed to eliminate any white coat effect or stress impact on the final results. The pre-test images were not analyzed. Then, 3-6 images were scanned. Immediately after SLDF, 3 measurements comprising systolic blood pressure (SBP), diastolic blood pressure (DBP), and heart pulse rate (HR) on the brachial artery were taken at 3-minute intervals using Omron M5/Japan. The mean arterial pressure (MAP) was calculated using the formula MAP $=(S B P-D B P) / 3+D B P$, and pulse pressure $(P P)$ was calculated using the formula $\mathrm{PP}=(\mathrm{SBP}-\mathrm{DBP})$. The BP parameter values of the 3 measurements were averaged.

Due to cataract, glaucoma or nystagmus, $16(9.2 \%)$ patients were excluded from the study group. The RCF, LD, and VD were analyzed, the WLR was calculated, and all the parameters were averaged to one mean value.

For the analyses, 158 patients (90.8\%) with T1DM (87 males, 71 females) and 38 controls (100\%; 19 males, 19 females) were included.

- Group A: Patients recently diagnosed with T1DM duration of less than 1 year; $n=40$, age $25.2 \pm 5.1$ years (mean \pm standard deviation), $43 \%$ women.

- Group B: Patients with T1DM duration exceeding 1 year but less than 11 years; $n=57$, age $24.0 \pm 4.9$ years; diabetes duration $5.4 \pm 2.7$ years, $39 \%$ women.

- Group C: Patients with T1DM duration exceeding 10 years; $n=61$, age $25.3 \pm 5.0$ years; diabetes duration $15.6 \pm 4.3$ years, $53 \%$ women.

- Control group: 38 nondiabetic adults, age $24.8 \pm 3.6$ years, $50 \%$ women.

Among the patients in group A, 7 were active smokers (17.5\%; examination performed at least 72 hours following last cigarette), 3 were smokers in group B (5.7\%), and none in group C. None of the patients in the first group, 2 patients in group B (3.8\%), and 3 patients in group C (4.5\%) were receiving antihypertensive treatment. The volunteers from the control group neither smoked nor were they taking any antihypertensive medication.

\section{Statistics analyses:}

The data were entered in an MS Excel spreadsheet (Microsoft, licensed to the Medical University of Gdańsk) and analyzed using Statistica version 10 (StatSoft PL, licensed to the Medical University of 
Gdańsk). The Shapiro-Wilk test was used to check for normality. Depending on whether the hypotheses were fulfilled or not, parametric and nonparametric tests (one-way ANOVA, Friedman's ANOVA, respectively) were used. Furthermore, the Pearson and Spearman's correlation coefficients were calculated. In the multivariate analysis, ANCOVA was performed to structure the key retinal parameters (i.e., WLR, RCF). Results with a p-value less than 0.05 ( two-sided) were considered statistically significant.

All the study procedures were performed in accordance with the Declaration of Helsinki for research involving human subjects as well as the requirements of the Ethical Committee of the University of Gdańsk, which approved the study (NKBBN/420/2012). Informed written consent was obtained from each participant.

\section{Results}

The clinical characteristics of the study patients and controls are presented in Table 1. All the patients and controls were normotensive; however, SBP, pulse pressure, and heart rate were significantly higher in groups $\mathrm{B}$ and $\mathrm{C}$ than in the controls and group $\mathrm{A}$ (Table 2 ).

Table 1

Comparison of age, BMI, and HbA1C between the groups. One-way ANOVA ( $p<0.001$ for the model with HbA1c comparisons)

\begin{tabular}{|lllll|}
\hline & Control & Group A & Group B & Group C \\
\hline Age (years) & $24.8 \pm 3.6$ & $25.2 \pm 5.1$ & $24.0 \pm 4.9$ & $25.3 \pm 5.0$ \\
\hline BMI & $23.9 \pm 4.1$ & $21.5 \pm 2.7$ & $22.8 \pm 4.1$ & $23.5 \pm 3.5$ \\
\hline HbA1C & - & $11.1 \pm 3.8$ & $7.8 \pm 1.9^{\wedge}$ & $8.0 \pm 1.7^{\wedge}$ \\
\hline $\begin{array}{l}\text { Group A - diabetes duration < 1 year; Group B - diabetes duration 1-10 years; Group C - diabetes } \\
\text { duration > 10 years; BMl - body mass index; HbA1C - glycated hemoglobin; ; } \mathrm{p}<0.05 \text { vs Group A }\end{array}$ \\
\hline
\end{tabular}


Table 2

Comparison of the blood pressure and heart rate between the study groups. One-way ANOVA

\begin{tabular}{|c|c|c|c|c|}
\hline & Control & Group A & Group B & Group C \\
\hline $\mathrm{SBP}(\mathrm{mmHg})$ & $115.0 \pm 13.2$ & $110.1 \pm 12.1$ & $121.9 \pm 9.7^{\wedge}$ & $123.8 \pm 15.7^{\ddagger}$ \\
\hline $\mathrm{DBP}(\mathrm{mmHg})$ & $75.0 \pm 8.2$ & $68.7 \pm 7.7^{\star}$ & $72.5 \pm 7.7$ & $75.3 \pm 8.4^{\ddagger}$ \\
\hline MAP $(\mathrm{mmHg})$ & $88.4 \pm 9.0$ & $82.4 \pm 8.3$ & $88.8 \pm 7.4$ & $91.3 \pm 9.1^{\ddagger}$ \\
\hline $\mathrm{PP}(\mathrm{mmHg})$ & $40.0 \pm 10.1$ & $41.4 \pm 9.4$ & $49.4 \pm 8.3^{*}$ & $48.4 \pm 14.5^{\star}$ \\
\hline HR (bpm) & $74.4 \pm 12.8$ & $76.9 \pm 9.2$ & $83.1 \pm 12.9$ & $92.4 \pm 13.7^{\star \star \neq 十 ~}$ \\
\hline \multicolumn{5}{|c|}{$\begin{array}{l}\text { Group } A \text { - diabetes duration }<1 \text { year; Group } B-\text { diabetes duration } 1-10 \text { years; Group } C-\text { diabetes } \\
\text { duration }>10 \text { years; DBP - diastolic blood pressure; HR - heart rate; MAP - mean arterial pressure; PF } \\
\text { - pulse pressure; SBP - systolic blood pressure; * } p<0.05 \text { vs control group; }{ }^{\wedge} p<0.05 \text { group B vs } \\
\text { group } A ;{ }^{\ddagger} p<0.05 \text { group } C \text { vs group } A ;{ }^{\dagger} p<0.05 \text { group } C \text { vs group B }\end{array}$} \\
\hline
\end{tabular}

The mean $\mathrm{HbA} 1 \mathrm{c}$ level was significantly higher in group $\mathrm{A}(11.1 \% \pm 3.8 \%)$ than in groups $\mathrm{B}$ and $\mathrm{C}(7.8 \% \pm$ $1.9 \%$ and $8.0 \% \pm 1.7 \%$, respectively). The $\mathrm{HbA} 1 \mathrm{c}$ difference between groups $\mathrm{B}$ and $\mathrm{C}$ was insignificant ( $\mathrm{p}$ $=0.47)$.

The patients in group $C$ had a significantly higher mean WLR compared to the control group ( 0.41 vs 0.33 , respectively; $p=0.001)$, group $A(\Delta W L R=0.11, p<0.001)$, and group $B(\Delta W L R=1.0, p<0.001)$ (Fig. 1$)$.

The mean RCF in group $A(R C F=297 \pm 121$ arbitrary units [AU]) was significantly higher compared to that of group $B(R C F=235 \pm 56 \mathrm{AU} ; p=0.007)$ and group $C(R C F=236 \pm 70 \mathrm{AU} ; p=0.008)$. The RCF difference between groups $B$ and $C$ was not significant $(p=0.99)$ (Fig. 2).

The other vascular parameters are presented in Table 3. In group $C$ hypertrophic vascular remodeling was detected as indicated by the high wall thickness and wall cross sectional area of the retinal arterioles. 
Table 3

Vascular characteristics measured with SLDF. One-way ANOVA.

\begin{tabular}{|c|c|c|c|c|}
\hline & Control & Group A & Group B & Group C \\
\hline $\mathrm{VD}(\mu \mathrm{m})$ & $111.7 \pm 13.3$ & $112.6 \pm 14.1$ & $109.9 \pm 15.2$ & $113.4 \pm 13.6$ \\
\hline $\mathrm{LD}(\mu \mathrm{m})$ & $84.5 \pm 9.3$ & $86.9 \pm 9.1$ & $84.4 \pm 11.7$ & $80.8 \pm 10.0$ \\
\hline $\mathrm{WT}(\mu \mathrm{m})$ & $13.7 \pm 4.5$ & $13.0 \pm 4.9$ & $12.8 \pm 3.3$ & $16.3 \pm 4.0^{\star^{\wedge} \dagger}$ \\
\hline WCSA $\left(\mu m^{2}\right)$ & $4273 \pm 1740$ & $4122 \pm 1948$ & $3958 \pm 1403$ & $5036 \pm 1707^{\dagger}$ \\
\hline \multicolumn{5}{|c|}{$\begin{array}{l}\text { Group A - diabetes duration }<1 \text { year; Group B - diabetes duration } 1-10 \text { years; Group C - diabetes } \\
\text { duration > } 10 \text { years; LD - lumen diameter; SLDF - scanning laser Doppler flowmetry; VD - vessel } \\
\text { diameter; WCSA - wall cross section area; WT - wall thickness; * } p<0.05 \text { vs control group; }{ }^{\wedge} p<0.05 \\
\text { group B vs group } A ;^{\dagger} p<0.05 \text { group C vs group B }\end{array}$} \\
\hline
\end{tabular}

\section{Discussion}

There were two main findings in our study. First, new-onset diabetes is associated with higher RCF compared to the RCF recorded in the patients with a longer duration of the disease. Second, structural arterial remodeling assessed as an increased WLR and WT is evident in the patients with a diabetes duration of 10 years or longer. These results could not be explained age, HBA1c or presence of hypertension. Neither RCF nor the structure of microcirculation was associated with any of the following: patient age, HbA1c concentration, and SBP. The only variable differentiating RCF and WLR was diabetes duration. These findings indicate that structural retinal changes observed in long-term type 1 diabetes are preceded by functional changes during early phase of the disease

Hyperglycemia has a profound impact on the cardiovascular system(15). A meta-analysis of 102 prospective studies prepared by the Emerging Risk Factors Collaboration showed only modestly a higher risk of coronary heart disease among people with no history of diabetes and a fasting glucose level below $7 \mathrm{mmol} / \mathrm{L}$ but a substantially higher risk in those with a fasting glucose of at least $7 \mathrm{mmol} / \mathrm{L}$ (hazard rate 1.17 vs $1.78 ; 1.61$ vs 2.36 in people with diabetes and the same fasting glucose values)(2).

Our knowledge regarding cardiovascular risk in T1DM is mainly based on the results of the Diabetes Control and Complications Trial (DCCT). The DCCT was a clinical trial conducted between 1983 and 1993 to check the hypothesis that the complications of T1DM could be delayed or prevented with the intensification of glucose control through intensive treatment. In total, 1441 patients were randomized either to the intensive treatment (INT) group or the conventional therapy (CON) group. The mean HbA1C at the end of the study was $7.2 \%(0.9 \%)$ for the INT group and $9.1 \%(1.3 \%)$ for the CON group. After the termination of the DCCT, the Epidemiology of Diabetes Interventions and Complications (EDIC) study was performed as a follow-up(16). The intima-media complex was measured at years 1 and 6 of the EDIC. Even though there were no significant differences between the diabetic and nondiabetic patients at year 1 of follow-up, after 6 years, the intima-media thickness of both the common and internal carotid arteries 
was significantly higher in the diabetic cohort, and the progression was more intensive in the CON group(17). The patients who were assigned to the INT group also had a much lower rate of cardiovascular events (i.e., nonfatal myocardial infarction, stroke, or death from cardiovascular disease) compared to the CON group ( 0.38 vs 0.80 , respectively; $p=0.007$ ) even though the risk was higher compared to the nondiabetic patients. No patients had hypertension or hypercholesterolemia at the beginning of the DCCT. The patients who experienced cardiovascular events during the EDIC were older, had a longer duration of diabetes, had higher $\mathrm{HbA} 1 \mathrm{C}$ and total and LDL cholesterol levels, a history of smoking, and a family history of myocardial infarction(18). Despite the cardiovascular risk, the presence of microangiopathic complications was also lower in the INT group(19). The follow-up period was similar in length to the duration of diabetes in group $\mathrm{C}$ in our study.

In our study, retinal flow was highest among the patients with new-onset diabetes and lower in the groups that had a longer duration of diabetes, among patients with $>1$ diabetes duration it was even lower then comparing to nondiabetic participants. These results could not be explained by the age of the patients as the patients enrolled in the study were within a narrow age interval.

Additionally, the patients who had recently been diagnosed with diabetes had higher glucose levels and significantly higher $\mathrm{HbA} 1 \mathrm{C}$ concentrations compared to glucose levels. This phenomenon may be similar to glomerular hyperfiltration, which is observed among patients with diabetes and even prediabetes(20). The mechanism is not completely understood but seems to be related to tubular factors and glomerular hemodynamics. This condition is present in about $50 \%$ of adolescents and young adults with diabetes. Hyperfiltration is thought to be a very important factor in diabetic kidney disease, likely as a reflection of the increased intraglomerular pressure resulting from structural changes(21). A significant decline in GFR is observed following hyperfiltration, which appears to present as normalized kidney function. Nonetheless, it is merely an interim state that further exacerbates the kidney damage, and this kidney damage is even greater compared to patients who do not present with hyperfiltration(5). This observation could be similar to our results describing retinal circulation. Chronic enzymatic glycation decreases endothelium-derived NO and increases not only the production of vasoconstrictor prostanoids and endothelin, but also the expression of cyklooxygenase-2. Furthermore, it impairs autonomic nervous function and alters the vascular smooth muscle synthesis of collagen. All the above mechanisms may contribute to vascular dysfunction(3). Our study provides novel insights into the relationship between T1DM and microcirculation impairment in patients without other cardiovascular risk factors such as hypertension, obesity, and aging.

Our study showed that the WLR was significantly higher among the patients with at least a 10-year course of diabetes compared to those with a shorter history of the disease and the healthy controls. Numerous studies have described the relationship between changes in the small arteries and increased cardiovascular risk leading to organ damage(22-24). Studies on hypertension have shown a significant correlation between BP and the WLR of retinal arterioles. Ritt et al. examined patients with never-treated essential hypertension and normotensive patients using SLDF(25). The arteriolar WLR in the retina among the patients with hypertension was 0.36 , and among the normotensive volunteers, it was 0.28 (the 
standard deviation was \pm 0.1 in both groups, $p=0.028$ ). There were also no significant differences in RCF (334 $\pm 84 \mathrm{AU}$ and $340 \pm 57 \mathrm{AU}$, respectively; $p=0.739$ ). A possible cause of the increased WLR in hypertensive patients may be hypertrophy of the smooth cell layer and/or remodeling. Additionally, apoptosis, inflammation, and fibrotic processes could contribute to arterial structure, with an abnormal balance between growth and apoptosis in hypertension(26). All these changes seem to be an adaptive response necessary to maintain an optimum level of wall tension. Despite the initial physiological adaptive response in chronic exposure to elevated BP levels, this leads to a maladaptive response and vascular complications of hypertension(25). Similar results were observed by Salvetti et al., who also examined normotensive patients in comparison to patients with treated or untreated hypertension(27). The WLR measured in the retinal arterioles in the patients without hypertension was $0.23 \pm 0.13$, while in the hypertensive individuals who were or were not receiving antihypertensive treatment, the WLR was $0.29 \pm 0.18$ and $0.28 \pm 0.18$, respectively. There was no significant difference between the hypertensive patients, but a significant difference was present when comparing the hypertensive patients and the normotensive individuals. An increased WLR of the retinal arterioles has also been found among patients diagnosed with primary aldosteronism or pheochromocytoma or after cerebrovascular events $(9,28,29)$. Among the patients enrolled in our study, BP was in the normotensive range. Nevertheless, the patients with a longer history of diabetes had significantly higher SBP, DBP, and MAP compared to the patients with new-onset diabetes, and SBP, DBP, and MAP in these patients tended to be higher than in the group of non-diabetic patients.

Strengths and limitations

We presented well-selected, relatively large groups of patients who did not differ in age or BMI. There was only a slight difference in smoking prevalence and antihypertensive treatment between the groups, with only a few participants either smoking or receiving antihypertensive medications (i.e., a low dose of ACE inhibitors to prevent albuminuria). SLDF is one of the most accurate methods for evaluating retinal microcirculation. Nevertheless, it is a somewhat subjective method operator-dependent. Therefore, we made every effort to reduce potential bias by carefully preparing and implementing a strict protocol, which has previously been used in a number of SLDF-based studies. We took at least 3 images of the retinal arterioles of each participant, and the data were averaged to reduce the possibility of measurement errors. All the images were blindly cross-checked by an investigator with long-standing expertise in the SLDF technique to identify images of unsatisfactory quality, which were subsequently excluded from further analysis. Additionally, when compared to already reported studies in which the SLDF technique was employed we enrolled relatively high number of patients to minimize method-related biases.

Potential limitations include lack of ambulatory blood pressure monitoring. Furthermore, our study was cross-sectional, and prospective observations are needed to gain more insights into the mechanisms underlying retinal microvascular abnormalities in type 1 diabetes.

\section{Conclusions}


Our study showed that new-onset T1DM is associated with higher RCF compared to patients with a longer duration of the disease. Furthermore, structural changes in retinal microcirculation among patients with T1DM were evident after at least 10 years. These findings may help improve the understanding of the mechanisms mediating the increased cardiovascular risk inherent to T1DM.

\section{Abbreviations}

AU - arbitrary units; BMI - body mass index; DBP - diastolic blood pressure; DCCT - Diabetes Control and Complications Trial; DM - diabetes mellitus; EDIC - Epidemiology of Diabetes Interventions and Complications; GFR - glomerular filtration rate; HbA1C - glycated haemoglobin; HR - heart pulse rate; LD - inner lumen; MAP - mean arterial pressure; NOS - nitric oxide synthase PP - pulse pressure; RCF - retinal capillary flow; SBP - systolic blood pressure; SLDF - scanning laser doppler flowmetry; T1DM - type 1 diabetes; VD - vessel diamaeter; WCSA - wall cross section area; WLR - wall-to-lumen ratio; WT - Wall thickness

\section{Declarations}

Conflict of interest:

The authors declare that they have no conflict of interest.

Acknowledgements

Authors would like to thank Elżbieta Orłowska-Kunikowska, Hanna Jasiel-Wojculewicz and Olga Kolcowa for their help in enrolment to the study.

Funding:

Not applicable' for that section.

Consent for publication:

Not applicable

Ethics approval and consent to participate:

All the study procedures were performed in accordance with the Declaration of Helsinki for research involving human subjects as well as the requirements of the Ethical Committee of the University of Gdańsk, which approved the study (NKBBN/420/2012). Informed written consent was obtained from each participant.

Availability of data and materials: 
The authors do not have written consent from study participants to make data and materials available for public access.

\section{Authors' contributions}

AS: performed the measurements, wrote and discussed the manuscript; JW: performed and interpreted statistical analysis, prepared results incl. graphics, wrote and discussed the manuscript; JMH: verified the quality of obtained images, wrote and discussed the manuscript; EMN: performed measurements; BW: enrolled participants and discussed the manuscript; KN: discussed and reviewed the manuscript; RES discussed and reviewed the manuscript. All authors read and approved the final manuscript.

\section{References}

1. Ogurtsova K, Fernandes JD da R, Huang Y, Linnenkamp U, Guariguata L, Cho NH, i in. IDF Diabetes Atlas: Global estimates for the prevalence of diabetes for 2015 and 2040. Diabetes Res Clin Pract. 1 czerwiec 2017;128:40-50.

2. Diabetes mellitus, fasting blood glucose concentration, and risk of vascular disease: a collaborative meta-analysis of 102 prospective studies. 2010;375:8.

3. Creager MA, Lüscher TF, prepared with the assistance of, Cosentino F, Beckman JA. Diabetes and Vascular Disease: Pathophysiology, Clinical Consequences, and Medical Therapy: Part I. Circulation. 23 wrzesień 2003;108(12):1527-32.

4. Sowers JR, Epstein M, Frohlich ED. Diabetes, hypertension, and cardiovascular disease: an update. Hypertens Dallas Tex 1979. kwiecień 2001;37(4):1053-9.

5. Bjornstad P, Cherney DZ, Snell-Bergeon JK, Pyle L, Rewers M, Johnson RJ, i in. Rapid GFR decline is associated with renal hyperfiltration and impaired GFR in adults with Type 1 diabetes. Nephrol Dial Transplant. październik 2015;30(10):1706-11.

6. Klein R, Knudtson MD, Lee KE, Gangnon R, Klein BEK. The Wisconsin Epidemiologic Study of Diabetic Retinopathy XXIII: the twenty-five-year incidence of macular edema in persons with type 1 diabetes. Ophthalmology. marzec 2009;116(3):497-503.

7. Delles C, Michelson G, Harazny J, Oehmer S, Hilgers KF, Schmieder RE. Impaired endothelial function of the retinal vasculature in hypertensive patients. Stroke. czerwiec 2004;35(6):1289-93.

8. Kannenkeril D, Harazny JM, Bosch A, Ott C, Michelson G, Schmieder RE, i in. Retinal vascular resistance in arterial hypertension. Blood Press. 2018;27(2):82-7.

9. Harazny JM, Ritt M, Baleanu D, Ott C, Heckmann J, Schlaich MP, i in. Increased Wall:Lumen Ratio of Retinal Arterioles in Male Patients With a History of a Cerebrovascular Event. Hypertension. październik 2007;50(4):623-9.

10. Bosch A, Scheppach JB, Harazny JM, Raff U, Eckardt K-U, Schmieder RE, i in. Retinal capillary and arteriolar changes in patients with chronic kidney disease. Microvasc Res. 2018;118:121-7. 
11. Cosentino F, Grant PJ, Aboyans V, Bailey CJ, Ceriello A, Delgado V, i in. 2019 ESC Guidelines on diabetes, pre-diabetes, and cardiovascular diseases developed in collaboration with the EASD: The Task Force for diabetes, pre-diabetes, and cardiovascular diseases of the European Society of Cardiology (ESC) and the European Association for the Study of Diabetes (EASD). Eur Heart J. 7 styczeń 2020;41(2):255-323.

12. Michelson G, Schmauss B, Langhans MJ, Harazny J, Groh MJ. Principle, validity, and reliability of scanning laser Doppler flowmetry. J Glaucoma. kwiecień 1996;5(2):99-105.

13. Harazny JM, Raff U, Welzenbach J, Ott C, Ritt M, Lehmann M, i in. New software analyses increase the reliability of measurements of retinal arterioles morphology by scanning laser Doppler flowmetry in humans: J Hypertens. kwiecień 2011;29(4):777-82.

14. Harazny JM, Schmieder RE, Welzenbach J, Michelson G. Local application of tropicamide $0.5 \%$ reduces retinal capillary blood flow. Blood Press. grudzień 2013;22(6):371-6.

15. Sarwar N, Aspelund T, Eiriksdottir G, Gobin R, Seshasai SRK, Forouhi NG, i in. Markers of Dysglycaemia and Risk of Coronary Heart Disease in People without Diabetes: Reykjavik Prospective Study and Systematic Review. Groop L, redaktor. PLoS Med. 25 maj 2010;7(5):e1000278.

16. Nathan DM, DCCT/EDIC Research Group. The diabetes control and complications trial/epidemiology of diabetes interventions and complications study at 30 years: overview. Diabetes Care. 2014;37(1):9-16.

17. Nathan DM, Lachin J, Cleary P, Orchard T, Brillon DJ, Backlund J-Y, i in. Intensive diabetes therapy and carotid intima-media thickness in type 1 diabetes mellitus. $\mathrm{N}$ Engl $\mathrm{J}$ Med. $5 \mathrm{czerwiec}$ 2003;348(23):2294-303.

18. Intensive Diabetes Treatment and Cardiovascular Disease in Patients with Type 1 Diabetes. N Engl J Med. 22 grudzień 2005;353(25):2643-53.

19. Lachin JM, Bebu I, Bergenstal RM, Pop-Busui R, Service FJ, Zinman B, i in. Association of Glycemic Variability in Type 1 Diabetes With Progression of Microvascular Outcomes in the Diabetes Control and Complications Trial. Diabetes Care. 2017;40(6):777-83.

20. Okada R, Yasuda Y, Tsushita K, Wakai K, Hamajima N, Matsuo S. Glomerular hyperfiltration in prediabetes and prehypertension. Nephrol Dial Transplant. 1 maj 2012;27(5):1821-5.

21. Bjornstad P, Cherney DZ, Maahs DM, Nadeau KJ. Diabetic Kidney Disease in Adolescents With Type 2 Diabetes: New Insights and Potential Therapies. Curr Diab Rep [Internet]. luty 2016 [cytowane 11 styczeń 2019];16(2). Dostępne na: http://link.springer.com/10.1007/s11892-015-0708-0

22. Rizzoni D, Porteri E, Boari GEM, De Ciuceis C, Sleiman I, Muiesan ML, i in. Prognostic Significance of Small-Artery Structure in Hypertension. Circulation. 4 listopad 2003;108(18):2230-5.

23. Wong TY, Klein R, Couper DJ, Cooper LS, Shahar E, Hubbard LD, i in. Retinal microvascular abnormalities and incident stroke: the Atherosclerosis Risk in Communities Study. Lancet Lond Engl. 6 październik 2001;358(9288):1134-40.

24. Park JB, Schiffrin EL. Small artery remodeling is the most prevalent (earliest?) form of target organ damage in mild essential hypertension. J Hypertens. maj 2001;19(5):921-30. 
25. Ritt M, Harazny JM, Ott C, Schlaich MP, Schneider MP, Michelson G, i in. Analysis of retinal arteriolar structure in never-treated patients with essential hypertension. J Hypertens. lipiec 2008;26(7):142734.

26. Intengan HD, Schiffrin EL. Vascular remodeling in hypertension: roles of apoptosis, inflammation, and fibrosis. Hypertens Dallas Tex 1979. wrzesień 2001;38(3 Pt 2):581-7.

27. Salvetti M, Agabiti Rosei C, Paini A, Aggiusti C, Cancarini A, Duse S, i in. Relationship of wall-to-lumen ratio of retinal arterioles with clinic and 24-hour blood pressure. Hypertens Dallas Tex 1979. maj 2014;63(5):1110-5.

28. Gosk-Przybylek M, Harazny J, Binczyk E, Szymanek K, Prejbisz A, Szaflik J, i in. 7D.11: RETINAL ARTERIOLAR STRUCTURE IN PATIENTS WITH PRIMARY ALDOSTERONISM. J Hypertens. 1 czerwiec 2015;33 Suppl 1-ESH 2015 Abstract Book:e103.

29. Prejbisz A, Harazny J, Szymanek K, Binczyk E, Gosk-Przybylek M, Szaflik J, i in. 7D.07: RETINAL ARTERIOLAR STRUCTURE IN PATIENTS WITH PHEOCHROMOCYTOMA. J Hypertens. 2015;33 Suppl $1: \mathrm{e} 102$.

\section{Figures}




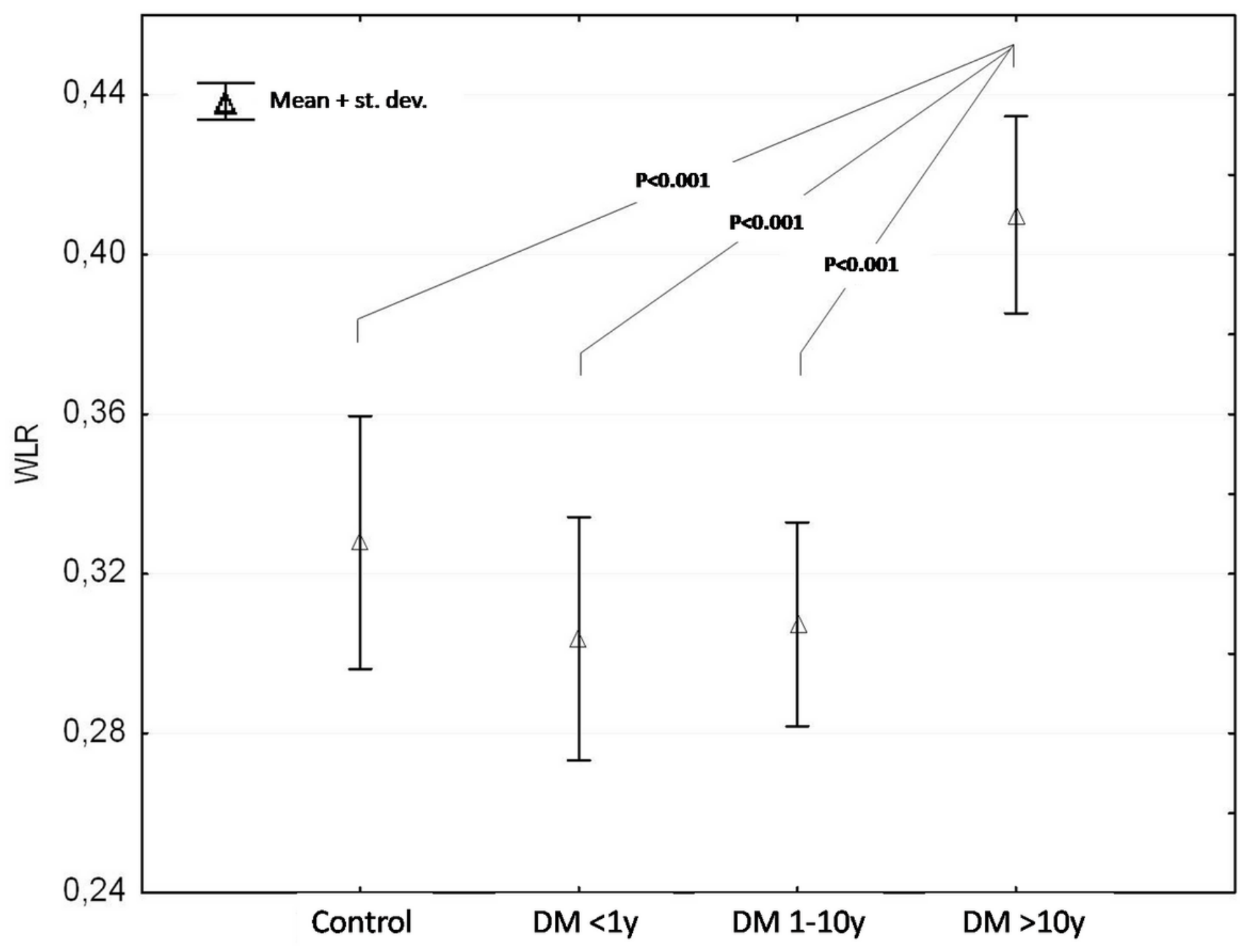

Figure 1

WLR in relation to diabetes duration. One-way ANOVA.

DM - diabetes mellitus; st. dev. - standard deviation; WLR - wall-to-lumen ratio 


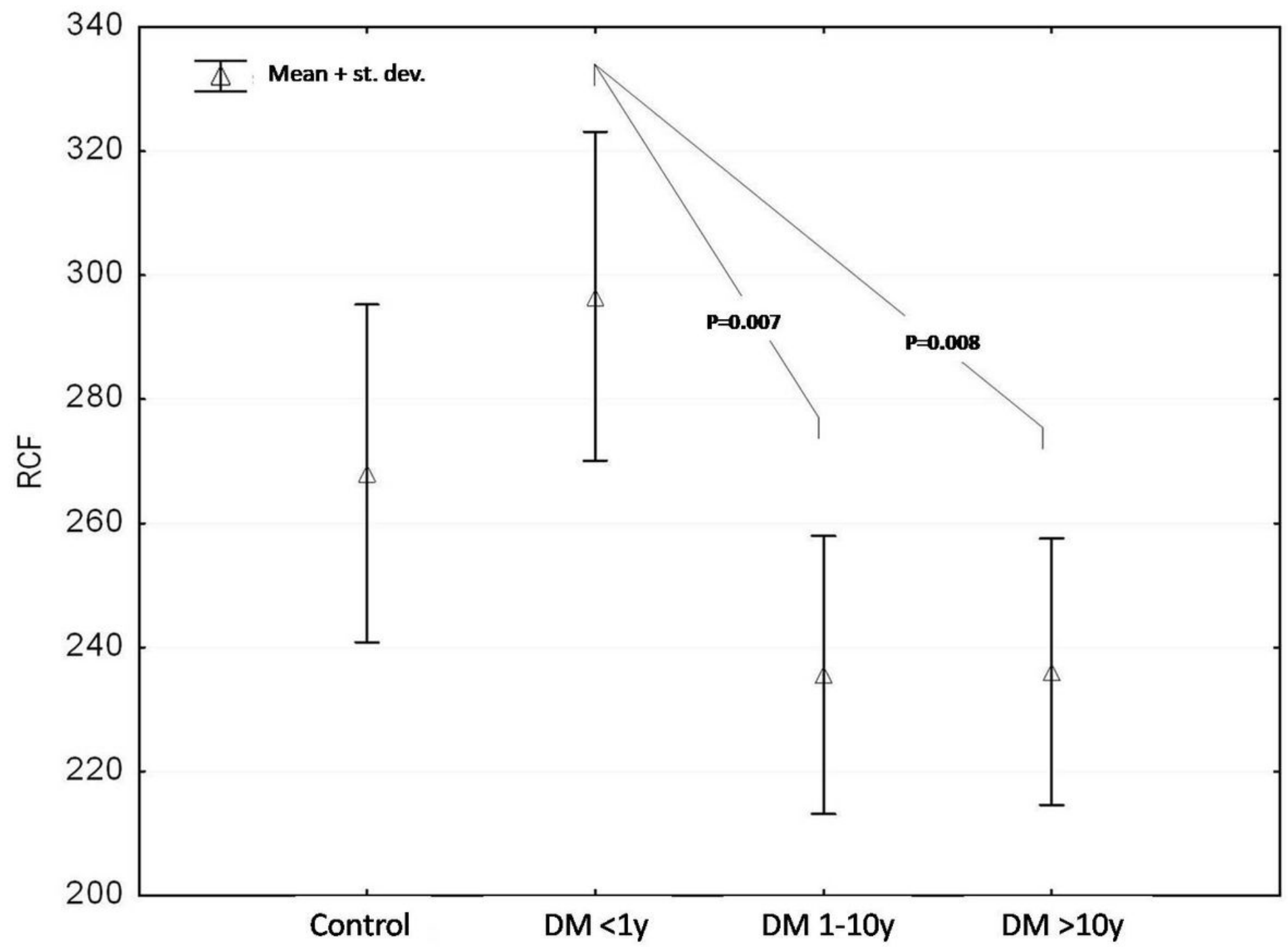

Figure 2

Mean retinal capillary flow in relation to duration of diabetes in the different groups. Blood flow expressed in arbitrary units (AU). One-way ANOVA with post-hoc Tukey test.

DM - diabetes mellitus; RCF - retinal capillary flow; st. dev. - standard deviation 